\title{
A large Turkish kindred with syndactyly type II (synpolydactyly). 1 Field investigation, clinical and pedigree data
}

\author{
Bekir Sitki Sayli, A Nurten Akarsu, Ugur Sayli, Okan Akhan, Serdar Ceylaner, \\ Mansoor Sarfarazi
}

Department of Medical Biology and Genetics, University of Ankara, Faculty of Medicine, Sihhiye, Ankara, Turkey

B S Sayli

A N Akarsu

Orthopedics Clinic, Etimesgut Community Hospital, Ankara, Turkey

U Sayli

Department of Radiology, University of Hacettepe, Faculty of Medicine, Sihhiye, Ankara, Turkey

O Akhan

Department of Medical Biology and Genetics,

University of

Erciyes,

Faculty of Medicine, Kayseri, Turkey

$\mathrm{S}$ Ceylaner

Surgical Research Centre, Department of Surgery, University of Connecticut Health Centre, Farmington, Connecticut 06030-1110, USA

A N Akarsu

M Sarfarazi

Correspondence to: Dr Sarfarazi.

Received 9 August 1994 Revised version accepted fo Revised version accepted for

\begin{abstract}
A very large Turkish family with syndactyly type II (synpolydactyly (SPD)) is described, which originated from and is mainly concentrated in the village of Derbent, Afyon. The kindred consists of 425 subjects over seven generations, of whom 182 are affected. It appears that a founder effect in this village has led to this extensive kindred. This condition is inherited as an autosomal dominant trait with variable expressivity and an estimated penetrance of $96 \%$. Penetrance is different between the upper $(96 \%)$ and lower $(69.5 \%)$ extremities. No excess of affected males or females or other associated features were documented in this condition. Variations in the involvement of one or both hands, upper or lower extremities, bone and soft tissue, as well as variation in the affected subjects of two successive generations were documented. We also noted that metacarpal and metatarsal involvement and middle phalangeal hypoplasia of the feet are the consistent features of SPD and, therefore, should be considered as characteristic of this phenotype. We observed four different phenotypes in various branches of the Derbent kindred: (1) subjects presenting typical features of SPD; (2) subjects exhibiting both pre- and postaxial polydactyly simultaneously; (3) persons manifesting postaxial polydactyly type $A$; and (4) subjects born to two affected parents with severe hand and foot deformities that have not been previously described in any other SPD families (that is, homozygotes). A total of 27 affected offspring were born to two such affected parents, of whom seven are expected to be homozygous for the SPD gene. This group is presented in an accompanying paper in this issue of the Journal. A molecular study is currently under way to identify the chromosomal location of the defective gene.
\end{abstract}

( $(\mathcal{M}$ Med Genet 1995;32:421-434)

Syndactyly as an isolated entity is classified in several ways, simple, complete, cutaneous, and osseous. ${ }^{1}$ Polydactyly, another congenital malformation of the hands and feet, generally appears preaxial or postaxial to the limb. ${ }^{2}$ Symmetrical or bilateral involvement, as in the involvement of all four limbs, has also been reported. ${ }^{3}$ The different anatomical types of isolated syndactyly and polydactyly have been presented clearly by Temtamy and McKusick. However, the clinical expression of various types of syndactyly may be more complicated, causing difficulties in proper classification. Furthermore, an alternative classification of the syndactylies and polydactylies has recently been proposed, based mainly on whether pattern formation is normal or abnormal, and whether secondary modelling of the limb bud appears to be defective. ${ }^{4}$

In some cases, syndactyly and polydactyly are found together. This is the case with syndactyly type II (synpolydactyly (SPD)), in which the third and fourth fingers as well as the fourth and fifth toes show syndactyly. This is usually associated with partial or complete reduplication of the same fingers and fifth toe. ${ }^{1}$

We describe here a very large and interesting Turkish kindred with SPD affecting 182 subjects, which originated from and is mainly concentrated in the village of Derbent, Afyon. The kindred spans at least 140 years and seven generations.

\section{Materials and methods} DESCRIPTION OF THE AREA

Derbent is a village in Bayat County, Afyon, an old mid-Anotolian city (fig 1) which is located about $8 \mathrm{~km}$ from Bayat on the AnkaraAfyon highway. It is not known when the village was established, but nearby ruins indicate that it is old. It was neglected over time and its inhabitants became impoverished. The village is inhabited by 1024 people in 107 dwellings in three quarters (Bayat Health Center Report, 1992). The population is mainly engaged in classical agriculture and husbandry. According to some of the elderly villagers, a woman from a neighbouring village who had come to Derbent as a bride brought with her this "unique hand and foot abnormality". However, there are several villages named Derbent in the middle county, and no-one remembers the

Table 1 The relationship between the circular pedigree and sub-pedigrees

\begin{tabular}{llc}
\hline Family No & Pedigree PID No & Circular PID No \\
\hline SPD-1 & 2 & III $\cdot 4$ \\
SPD-2 & 1 & II $\cdot 2$ \\
SPD-3 & 1 & II $\cdot 3$ \\
SPD-4 & 1 or 2 & I 2 \\
SPD-5 & 1 III 18 \\
SPD-6 & 1 or 2 & II $\cdot 9$
\end{tabular}




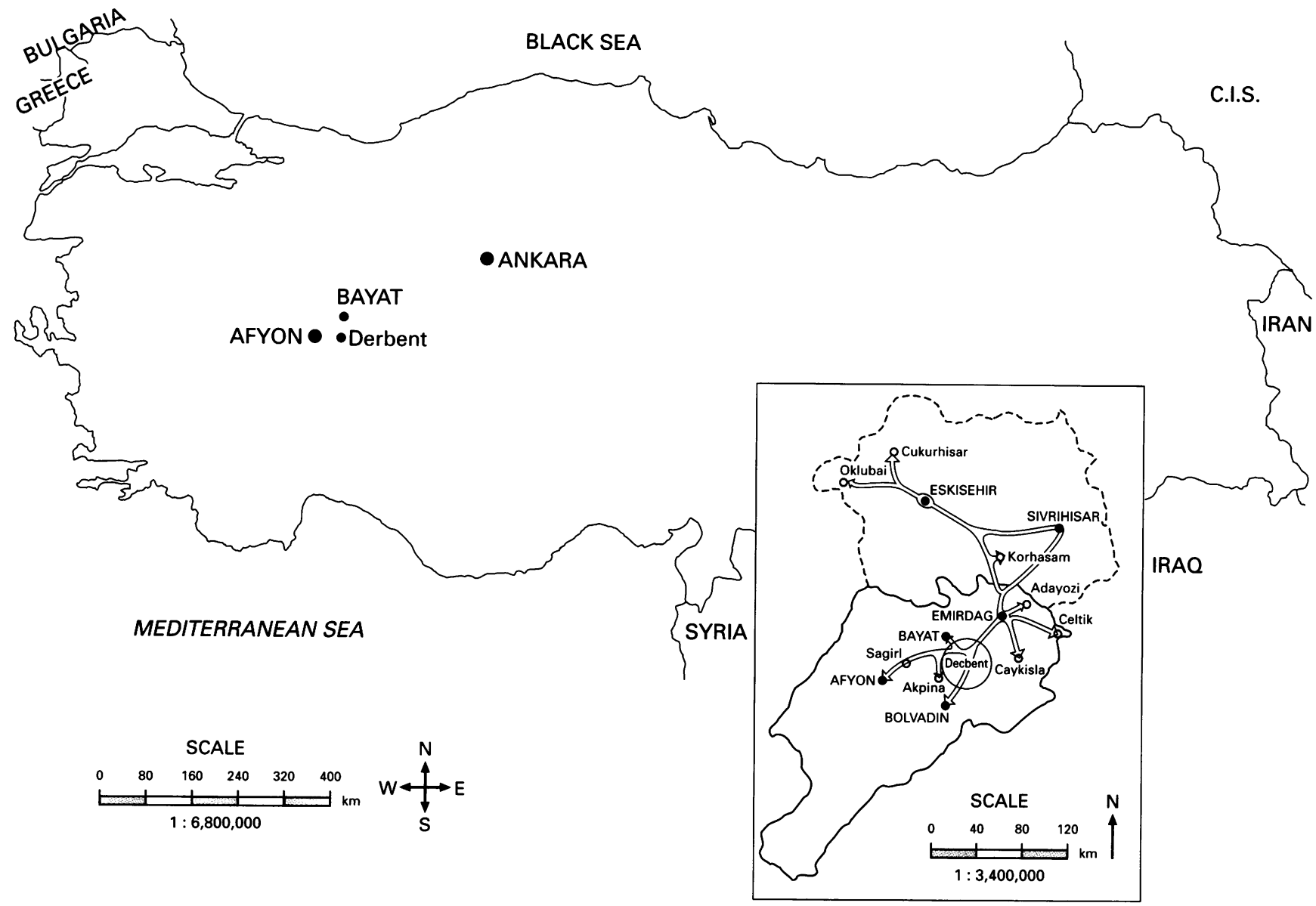
Figure 1 Map of Turkey showing the origin of the synpolydactyly gene in the village of Derbent and its spread to the neighbouring areas (inset map).
Distances are shown on the scale bar.

woman's name or when she arrived. As can be predicted from the pedigree (fig 2), this condition had to have occurred at least 140 to 150 years ago. Despite its longstanding presence, neither medical practitioners nor laymen (including politicians) have ever paid attention to the condition. Surgery was performed on one person's hand many years ago, with no further interest being shown. This village and the affected inhabitants have come to public attention through a television programme, making this study urgent and feasible.

\section{FIELD INVESTIGATION}

An extensive study was planned by a team of physicians (including the authors) following the first visit to Derbent. Affected and unaffected subjects were interviewed either in their homes or in a mutually convenient central location. Pedigrees were constructed by repeatedly checking and reviewing all records related to births and deaths from the year 1906 onwards.
The genealogy has been traced back to four subjects in a single generation, but as yet we have not been able to confirm that the SPD phenotype originated from a single person. The circular pedigree was constructed as a pictorial representation of all pedigrees combined (fig 2). Details of the findings on physical examination are summarised on each individual sub-pedigree (fig 3A-F). The heterozygotes in these pedigrees are shown as half shaded and the homozygotes as fully shaded symbols. The sub-pedigrees were constructed by deduction from the circular pedigree. The common personal identification numbers (PID) between the circular and sub-pedigrees are shown in table 1.

Physical examinations were carried out with emphasis on the details of the hand and foot malformations. $X$ ray films were obtained at a nearby centre. Some subjects were asked to go to Ankara for thorough evaluation and orthopaedic management. So far, routine laboratory tests have been done only on those subjects

Table 2 Distribution of subjects in the Derbent kindred

\begin{tabular}{|c|c|c|c|c|c|c|c|c|c|}
\hline \multirow[t]{2}{*}{ Status } & \multicolumn{3}{|c|}{ Living } & \multicolumn{3}{|c|}{ Dead } & \multicolumn{3}{|c|}{ Total } \\
\hline & $M$ & $F$ & Sum & $M$ & $F$ & Sum & $M$ & $F$ & Sum \\
\hline $\begin{array}{l}\text { Affected } \\
\text { Normal } \\
\text { Sums } \\
\text { Unknowns } \\
\text { Spouses } \\
\text { Totals }\end{array}$ & $\begin{array}{r}72 \\
63 \\
135 \\
0 \\
19 \\
154\end{array}$ & $\begin{array}{r}77 \\
75 \\
152 \\
0 \\
19 \\
171\end{array}$ & $\begin{array}{r}149 \\
138 \\
287 \\
0 \\
38 \\
325\end{array}$ & $\begin{array}{r}18 \\
11 \\
29 \\
8 \\
19 \\
56\end{array}$ & $\begin{array}{r}15 \\
6 \\
21 \\
6 \\
17 \\
44\end{array}$ & $\begin{array}{r}33 \\
17 \\
50 \\
14 \\
36 \\
100\end{array}$ & $\begin{array}{r}90 \\
74 \\
164 \\
8 \\
38 \\
210\end{array}$ & $\begin{array}{r}92 \\
81 \\
173 \\
6 \\
36 \\
215\end{array}$ & $\begin{array}{r}182 \\
155 \\
337 \\
14 \\
74 \\
425\end{array}$ \\
\hline
\end{tabular}




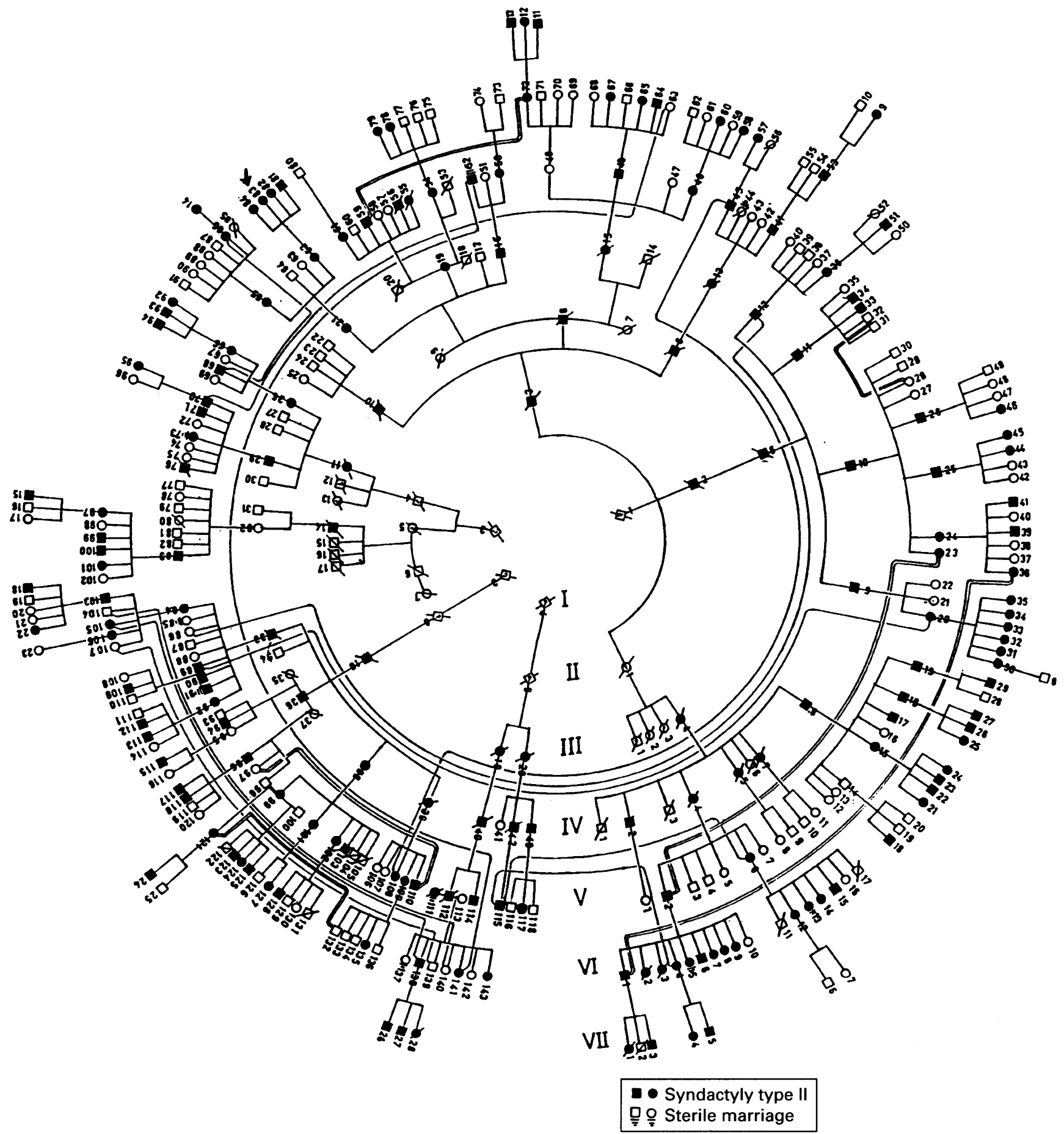

Figure 2 The circular representation of the Derbent pedigree. The proband is shown by an arrow. In order to simplify the pedigree, we have shown all the people with various types of SPD by solid symbols, unaffected people by open symbols and have shown only the children of affected subjects and not those of the normal subjects. Details of this kindred are presented in each individual sub-pedigree (fig $3 A-F)$.

visiting Ankara, and corrective operations have been planned or performed on a number of them.

\section{Results}

There are 182 people affected with the SPD phenotype, of whom 33 have now died (table 2 ). There are no written records of their malformations, but they were accurately described by family members. We examined 106 subjects and obtained $x$ rays from 41 affected people and one non-penetrant heterozygote. Interesting physical and radiological variations as well as phenotypic differences were noted. With respect to the phenotype, we have been able to discriminate the following four major groups of malformations in the same kindred: (1) those presenting typical features of the SPD phenotype; (2) those showing both pre- and postaxial SPD simultaneously; (3) those having postaxial polydactyly type A; and (4) those with bilateral, complete, complex SPD (that is, probable homozygotes). The distribution of subjects in these groups is shown in table 3 .

In this paper, a clinical description of the first three groups will be presented. The last group is presented in an accompanying manuscript in order to elucidate the complete characteristics of these previously undescribed homozygotes. 

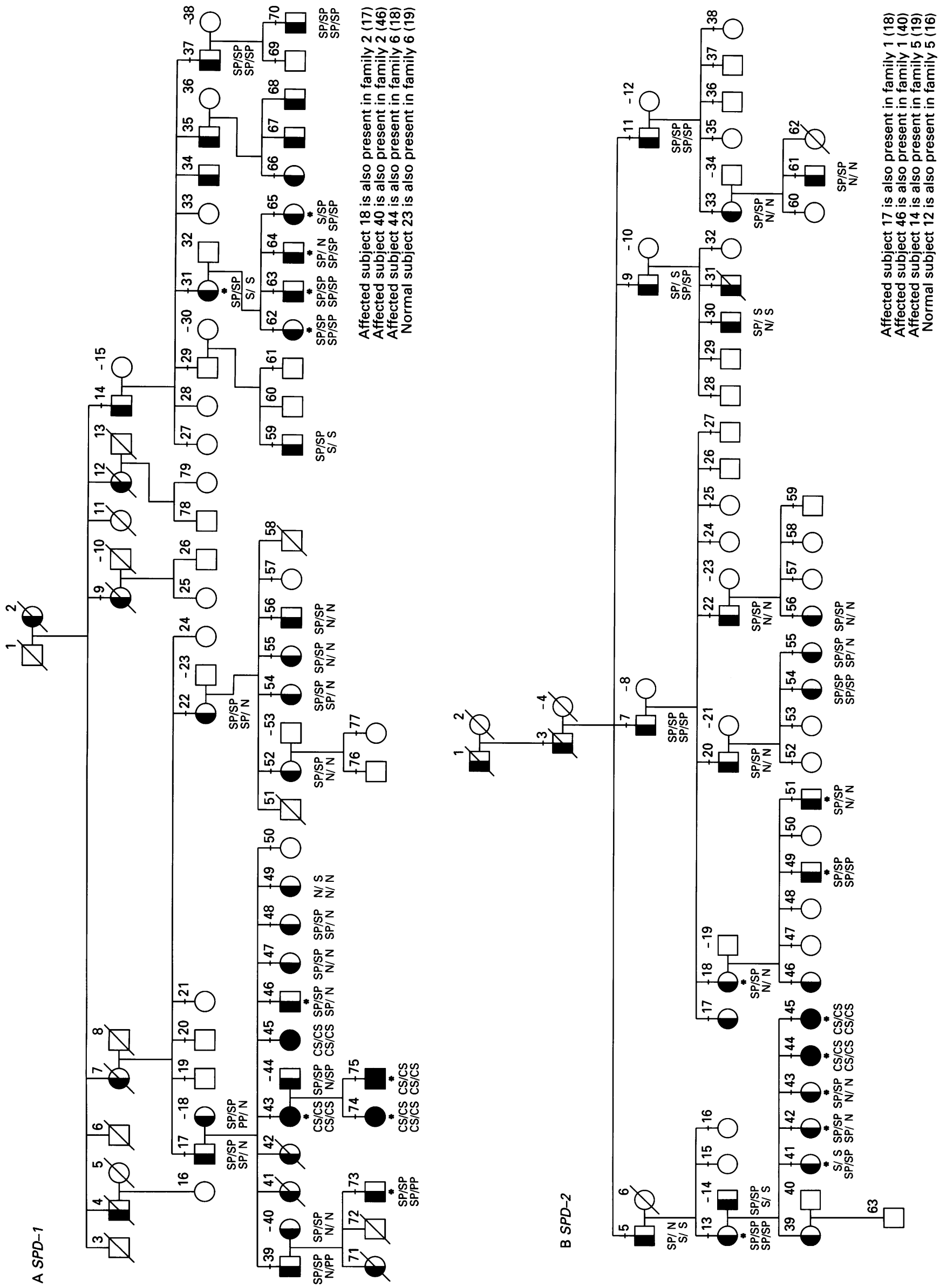


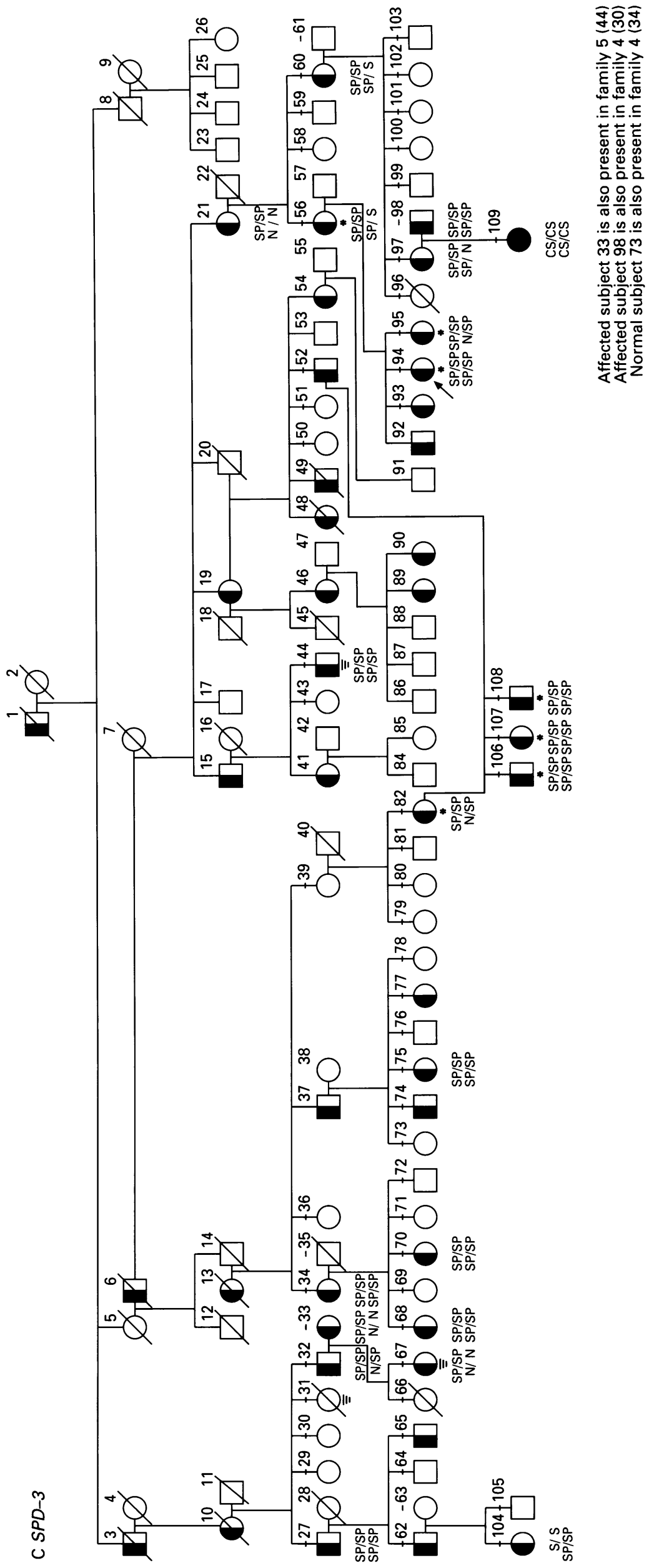




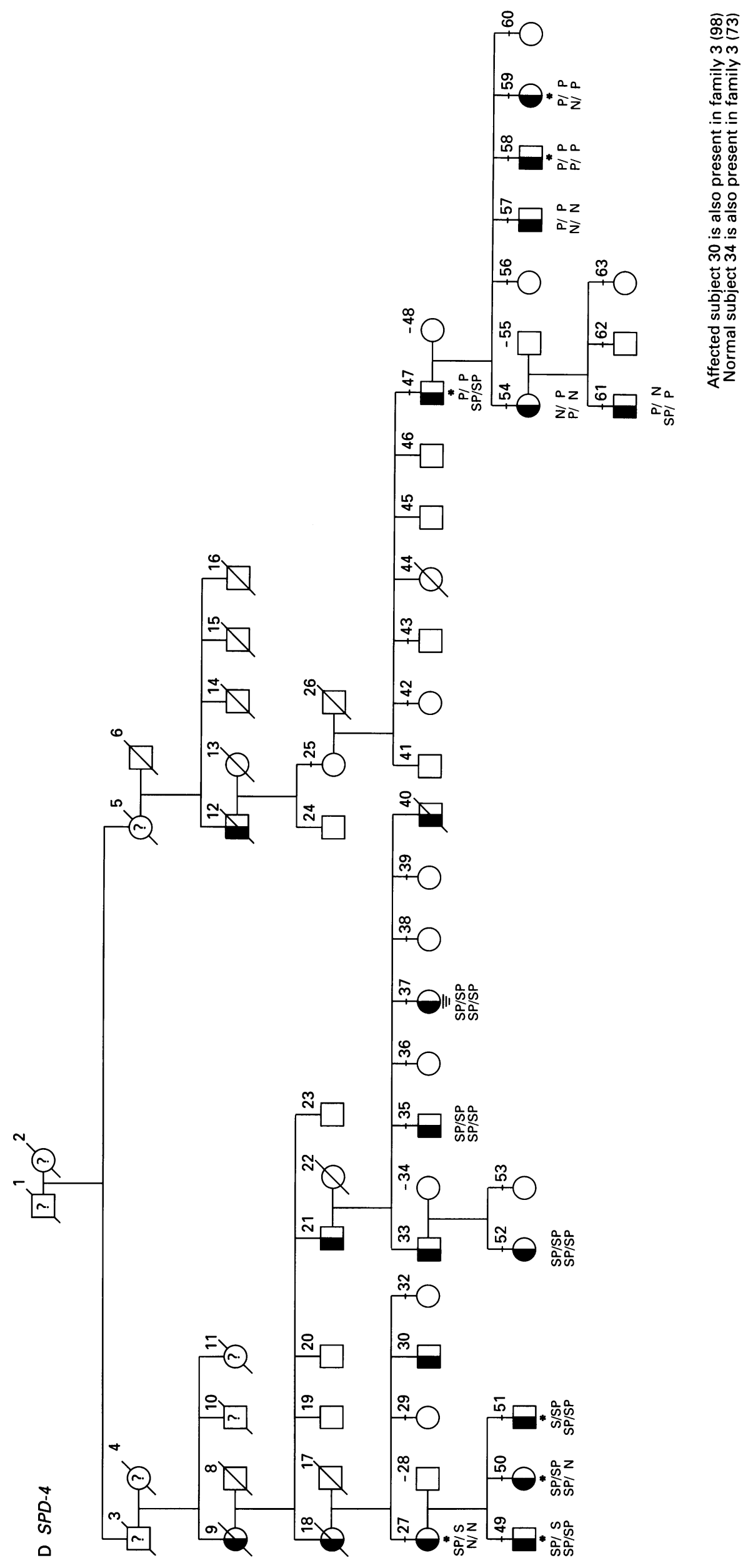



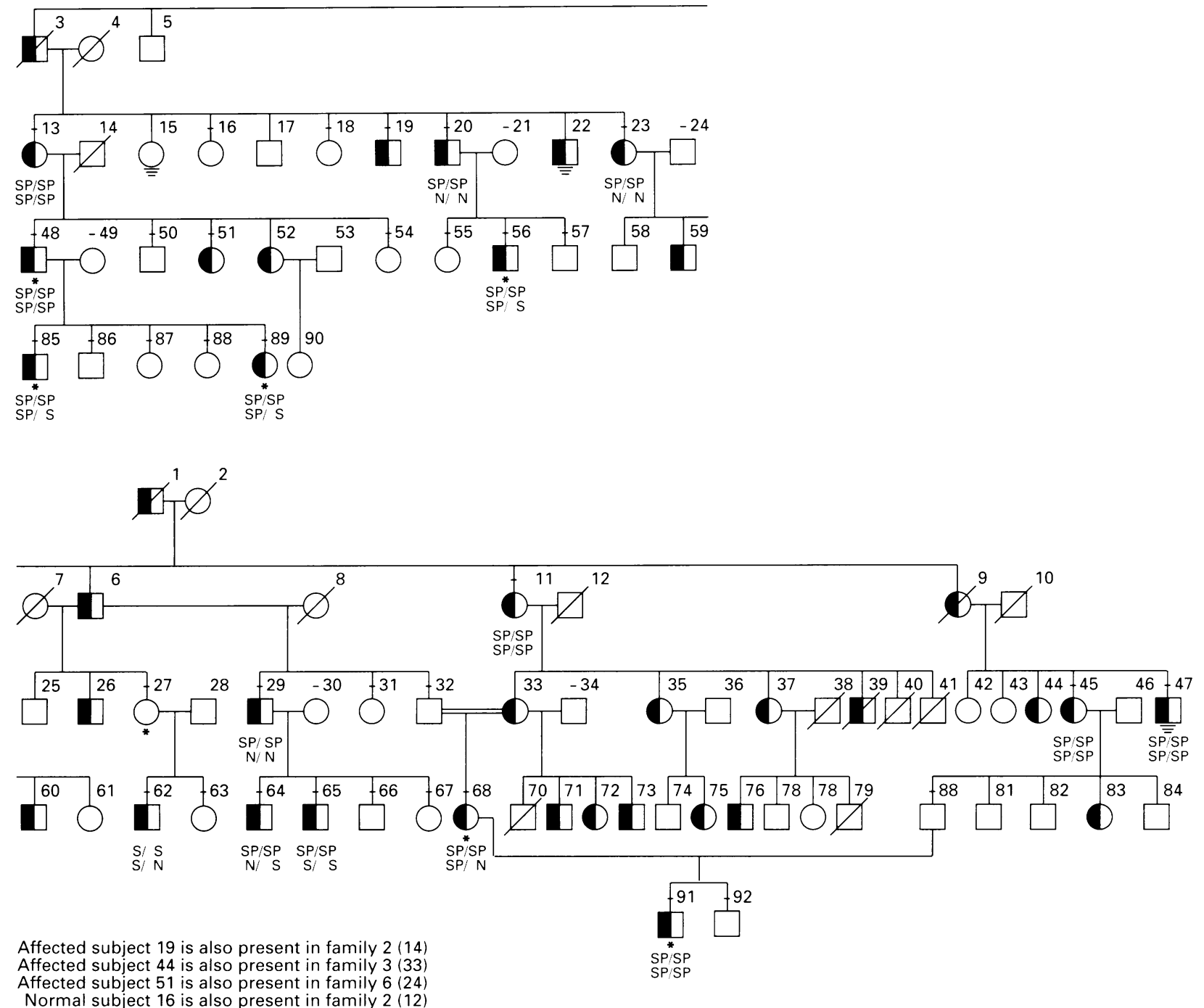

Affected subject 44 is also present in family $3(33)$

Normal subject 16 is also present in family $2(12)$

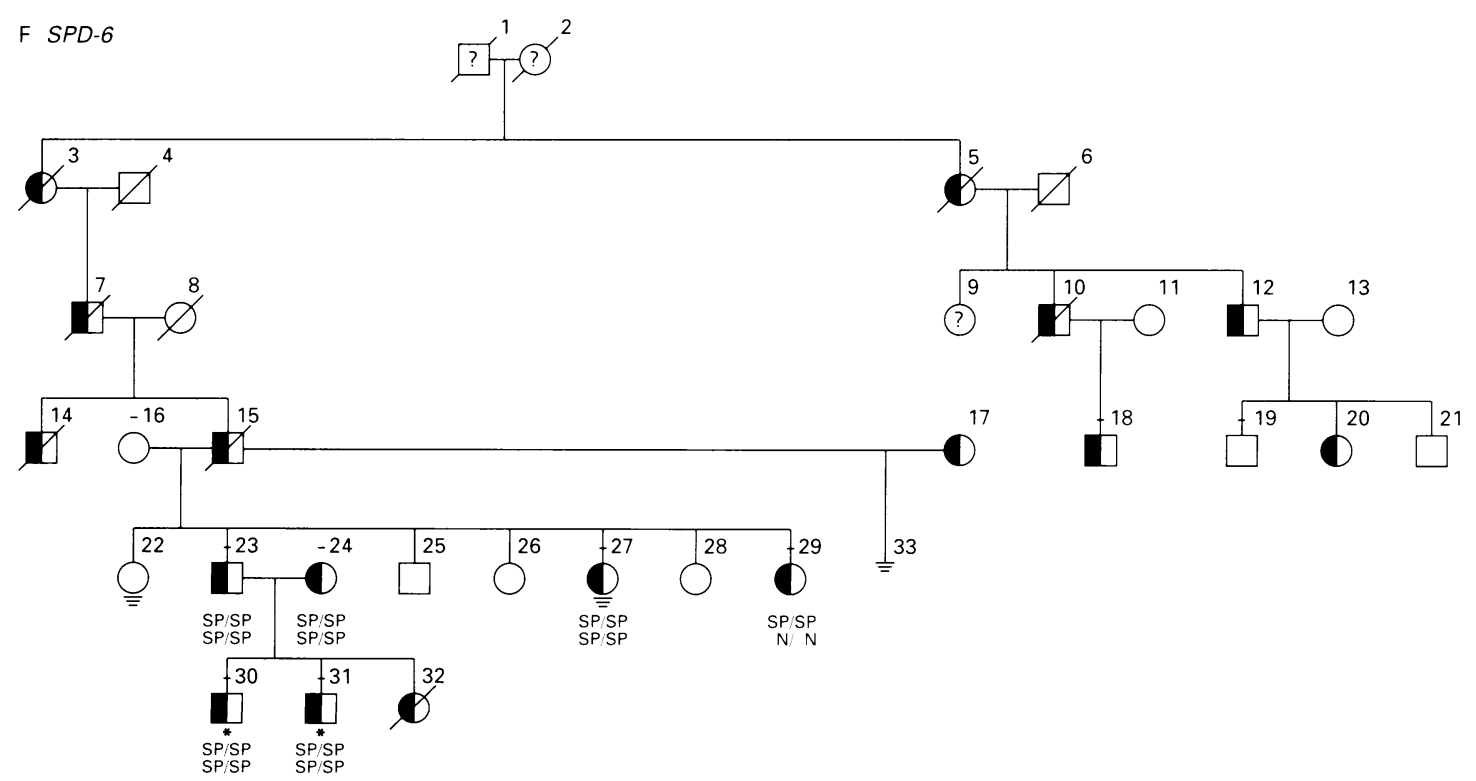

Affected subject 24 is also present in family $5(51)$

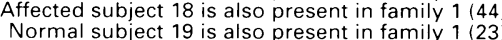

Figure $3 \mathrm{~A}-\mathrm{F}$ The individual sub-pedigrees of SPD1-SPD6. Duplicated subjects are indicated for each kindred. The heterozygous SPD phenotype is shown by half shaded symbols, while the seven homozygotes are completely shaded. $A$ star $\left(^{*}\right)$ below each symbol indicates that $x$ ray was obtained. The following two lines are the observed phenotype in hands (right/left) and feet (right/left) respectively: The abbreziations used are: $N=$ normal; $S=$ syndactyly; $P=$ polydactyly; $S P=$ synpolydactyly; $C S=$ complex syndactyly (homozygotes); and $P P=$ preaxial polydactyly: 
Table 3 Distribution of subjects into four main groups as seen in the synpolydactyly population according to physical examination and $x$ ray findings

\begin{tabular}{lllllr}
\hline & Typical SPD & Pre-postaxial SPD & $\begin{array}{l}\text { Postaxial polydactyly } \\
\text { type A }\end{array}$ & Complete complex SPD & Total \\
\hline Female & 48 & 1 & 2 & 6 & 57 \\
Male & 42 & 2 & 4 & 1 & 49 \\
Total & 90 & 3 & 6 & 7 & 106 \\
\hline
\end{tabular}

Table 4 Distribution of the subjects with respect to sex as well as bilateral or unilateral involvement in the upper and lower limbs

\begin{tabular}{|c|c|c|c|c|c|c|c|c|c|c|c|c|}
\hline & & \multirow{2}{*}{$\begin{array}{l}\text { Type of } \\
\text { malformation }\end{array}$} & \multicolumn{4}{|c|}{ Right hand } & & \multirow{2}{*}{$\begin{array}{l}\text { Type of } \\
\text { malformation }\end{array}$} & \multicolumn{4}{|c|}{ Right foot } \\
\hline & & & $S p$ & $S$ & $N$ & Total & & & $S p$ & $S$ & $N$ & Total \\
\hline Male & $\begin{array}{l}\text { Left } \\
\text { hand }\end{array}$ & $\begin{array}{l}\mathrm{Sp} \\
\mathrm{S} \\
\mathrm{N} \\
\text { Total }\end{array}$ & $\begin{array}{r}36 \\
2 \\
2 \\
40\end{array}$ & $\begin{array}{l}1 \\
1 \\
2\end{array}$ & $\begin{array}{l}- \\
- \\
- \\
-\end{array}$ & $\begin{array}{r}37 \\
3 \\
2 \\
42\end{array}$ & $\begin{array}{l}\text { Left } \\
\text { foot }\end{array}$ & $\begin{array}{l}\mathrm{Sp} \\
\mathrm{S} \\
\mathrm{N} \\
\text { Total }\end{array}$ & $\begin{array}{r}21 \\
2 \\
3 \\
26\end{array}$ & $\begin{array}{l}- \\
4 \\
1 \\
5\end{array}$ & $\begin{array}{r}2 \\
2 \\
7 \\
11\end{array}$ & $\begin{array}{r}23 \\
8 \\
11 \\
42\end{array}$ \\
\hline Female & $\begin{array}{l}\text { Left } \\
\text { hand }\end{array}$ & $\begin{array}{l}\mathrm{Sp} \\
\mathrm{S} \\
\mathrm{N} \\
\text { Total }\end{array}$ & $\begin{array}{r}42 \\
2 \\
- \\
44\end{array}$ & $\begin{array}{l}1 \\
2 \\
-3\end{array}$ & $\begin{array}{l}\overline{1} \\
\overline{1}\end{array}$ & $\begin{array}{r}43 \\
5 \\
- \\
48\end{array}$ & $\begin{array}{l}\text { Left } \\
\text { foot }\end{array}$ & $\begin{array}{l}\mathrm{Sp} \\
\mathrm{S} \\
\mathrm{N} \\
\text { Total }\end{array}$ & $\begin{array}{r}21 \\
2 \\
7 \\
30\end{array}$ & $\begin{array}{l}\overline{1} \\
\overline{1}\end{array}$ & $\begin{array}{c}2 \\
- \\
15 \\
17\end{array}$ & $\begin{array}{r}23 \\
3 \\
22 \\
48\end{array}$ \\
\hline
\end{tabular}

$\mathrm{Sp}=$ synpolydactyly, $\mathrm{S}=$ syndactyly, $\mathrm{N}=$ normal.

(1) SUBJECTS PRESENTING TYPICAL FEATURES OF SPD

Of 106 patients who were physically examined, there are 90 subjects ( 42 males and 48 females) with typical features of SPD (table 3). Since it is impossible to detail the clinical findings in 90 subjects, one person (fig $2, \mathrm{VI} \cdot 83$ and fig $3 \mathrm{C}$, PID 94) has been arbitrarily chosen as the proband for detailed presentation. Others are presented briefly in each individual pedigree and are also grouped together in table 4.

The proband is a 13 year old female affected with syndactyly type II in both hands and feet. No other associated features were found in this person. She has had no difficulty at all with housekeeping or yard work.

There were six fingers on both hands, with the third being duplicated, as well as soft tissue syndactyly involving the third to the sixth digits. In addition, the last digit showed clinocamptodactyly (fig 4A). The fingernails were normal and no serious limitation of movement of the hand joints was noted. $X$ rays showed six fingers and duplicated third metacarpals in a bifid shape on both sides (fig $4 \mathrm{~B}$ ). The fifth finger showed clinodactyly with middle phalangeal hypoplasia on both sides.

There were six toes with duplication and synostosis of the fifth and sixth ones (fig 4C). Syndactyly involved the fourth, fifth, and sixth toes. The nails of the synostotic toes were dysmorphic. $X$ rays showed six digits on both sides. The fifth and supernumerary toes were fused in a $\mathrm{Y}$ shaped deformity, being more conspicuous on the right (fig 4D). The middle and distal phalanges of all digits were rudimentary and fused, except for the big toe. In addition to five metatarsals, a small piece of extra bone was interspersed between the last two metatarsals. This extra bone was synostotic with the sixth toe and was somewhat longer on the left (fig 4E).

Excluding the proband, there remain 89 people who were physically examined manifesting the SPD phenotype. Additionally, significant inter- and intrafamilial variations have been noted. Variations can be classified as: (1) variation in the involvement of one or both hands; (2) variation in the involvement of upper or lower extremities; (3) variation in the bones and soft tissues involved; and (4) variation in affected subjects of two successive generations. It is not feasible to present all of the variations observed so far, but they are summarised on each sub-pedigree (fig 3A-F). The distribution of subjects with respect to sex as well as bilateral or unilateral involvement in the upper and lower limbs is shown in table 4.

Briefly, in 87 out of a total of $90(96.7 \%)$ typical SPD cases, hand involvement was bilateral, and in the remaining three cases $(3.3 \%)$ it was unilateral. In the feet, the affliction was bilateral in $51(56.7 \%)$ and unilateral in 17 $(18.9 \%)$, and in the remaining 22 subjects $(24 \cdot 4 \%)$ the feet were normal. There were no cases with affected feet but normal hands.

With respect to asymmetrical involvement, there was only one case with a completely normal hand and foot on the right side, but with characteristic changes on the left (fig $3 \mathrm{~A}$, subject 49 ). There were no cases with a normal hand and foot on the left. Therefore, the two sides cannot be compared. However, if we ignore hand involvement, there were 11 cases with a normal foot on the left, but an affected one on the right. Conversely, there were only six cases with a normal foot on the right, but an affected foot on the left. The right foot is approximately twice as often affected as the left with the male/female ratio being $4 / 7$ (57\%).

If cases are regarded with respect to involvement of all four limbs (tetrasyndactyly/ tetrasynpolydactyly), then no significant difference was observed between the two sexes (table 5).

$X$ ray films were obtained in 42 subjects, of whom 31 showed the typical SPD phenotype (14 males, 17 females). Carpal and tarsal bones were normal in all cases. Metacarpal bones were normal in six subjects $(19.3 \%)$ and abnormal in the remaining $25(80 \cdot 7 \%)$, with both structural and numerical abnormalities. In the latter, an 

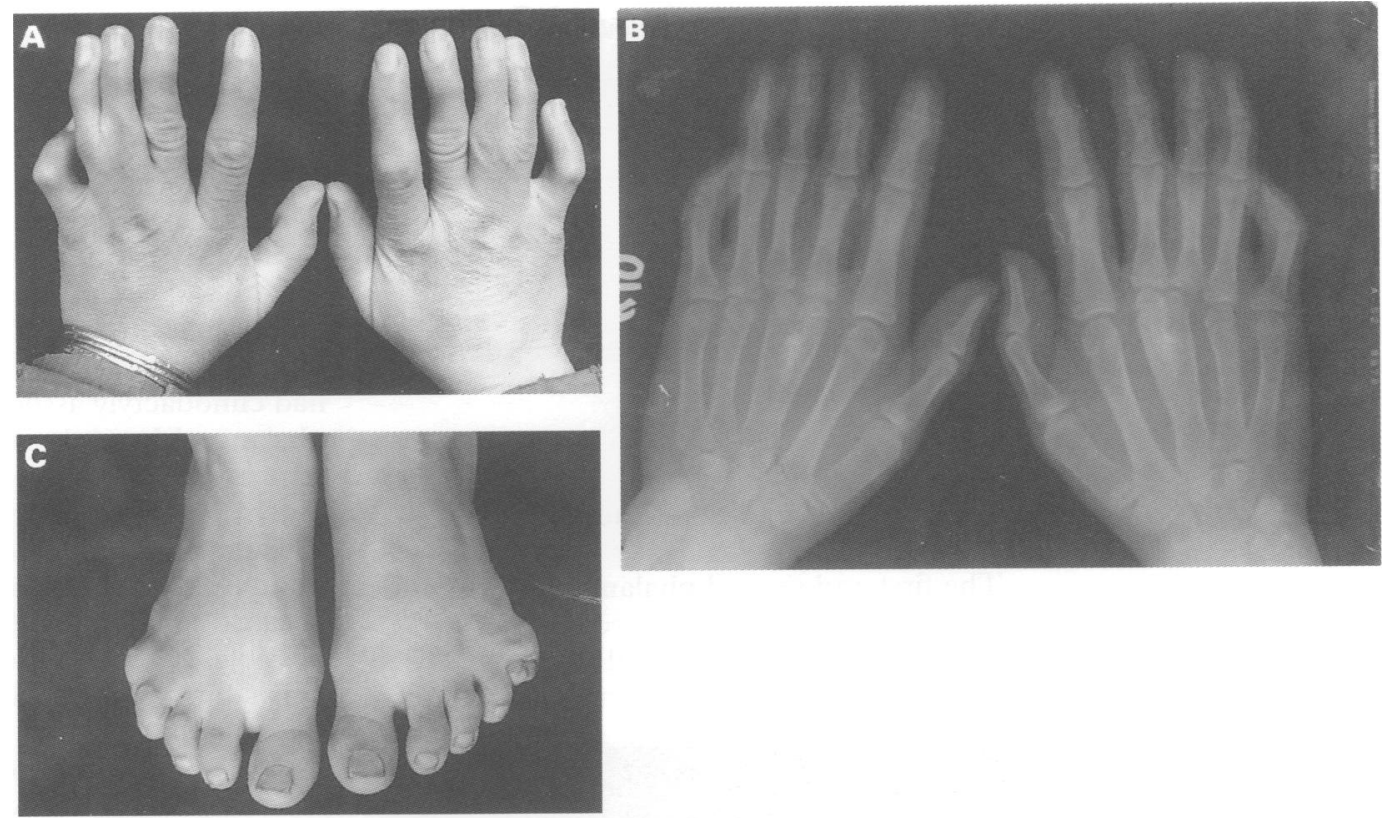

Table 5 Distr
involvement

\begin{tabular}{llll}
\hline & Female & Male & Total \\
\hline Four limb involvement & 24 & 25 & 49 \\
At least one normal limb & 24 & 17 & 41 \\
Total & 48 & 42 & 90
\end{tabular}

$\chi_{1}^{2}=0 \cdot 816 ; p=0 \cdot 37$ abnormality bilaterally. However, 10 cases out of $25(40 \%)$ had one type of abnormality in one hand, but a different one in the other. An extra bone was interspersed between the third and fourth metacarpal bones in 14 out of 25 (56\%) subjects, so this abnormality was the most frequent malformation of the metacarpal bones.

Metatarsal bones were normal in five persons $(16 \cdot 1 \%)$ and abnormal in the remaining 26 $(83.9 \%)$. There were six metatarsal bones in all 26 cases. The extra one was either well shaped or composed of rudimentary bone particles, but it was always placed between the fourth and fifth metatarsal bones. In eight cases, the basal part of the second metatarsal bone was enlarged in an exostosis-like fashion (fig 5, arrow). Unfortunately, $x$ ray films were not available for all the family members of the person shown in fig 5 . However, this branch showed the same abnormality in the mother 
Table 6 Distribution of abnormalities of metacarpal bones with respect to the right and left hands

\begin{tabular}{llcccccc}
\hline \multicolumn{7}{c}{ Right metacarpal bones } \\
\cline { 2 - 8 } & & $A$ & $B$ & $C$ & $D$ & Normal & Total \\
\hline Left metacarpal & A & 8 & - & 1 & 1 & - & 10 \\
bones & B & - & - & 1 & - & - & 1 \\
& C & 2 & - & 3 & 1 & 2 & 8 \\
& D & 1 & - & - & 4 & 6 & 7 \\
& Normal & 1 & - & - & - & 6 & 31 \\
\hline
\end{tabular}

A: An extra piece of bone between third and fourth metacarpal bones B: An extra piece of bone between fourth and fifth metacarpal bones C: Y shaped deformity

D: Bifid bony structure

(fig 3A, PID 31) and two of her offspring (PID 62 and 65 ).

The first and second phalanges of the hands were normal in all cases except one (fig $3 \mathrm{C}$, PID 95). In this exceptional case, the distal parts of the proximal phalanges were hypo-

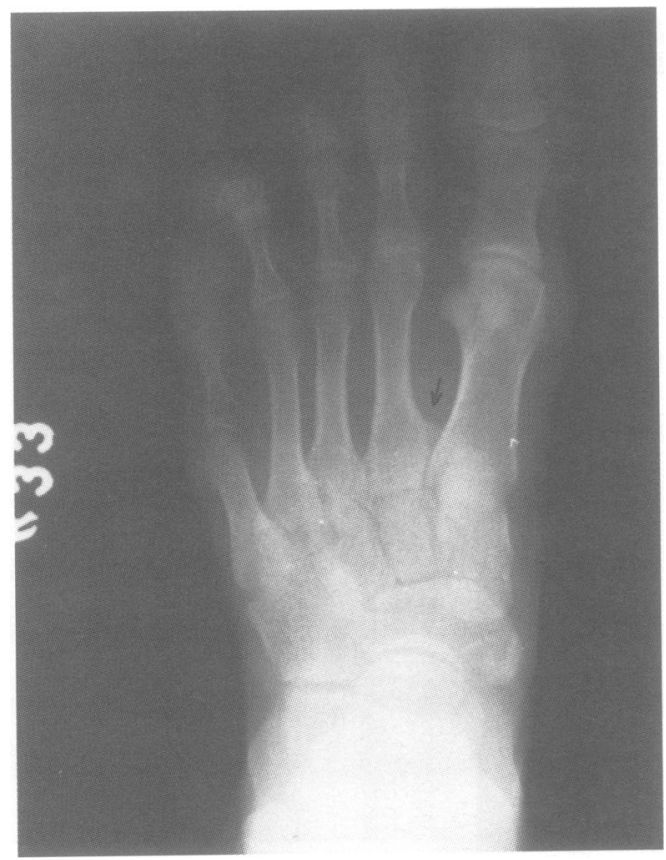

Figure 5 Subject 31 in SPD-1 showing the enlarged basal part of the second metatarsal bone (arrow).

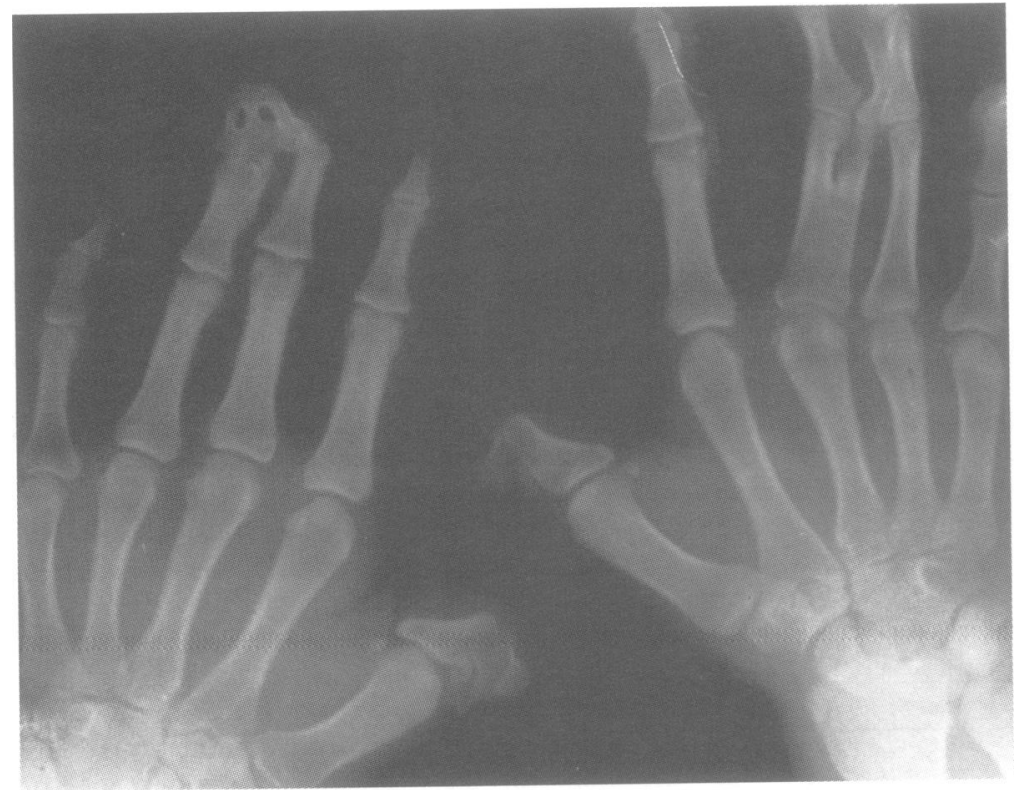

Figure 6 Subject 95 in SPD-3 with first finger abnormality showing hypoplastic proximal phalanges which are contracted in a hyperextended position. plastic and the distal phalanges were contracted in a hyperextended position in both hands (fig 6). $X$ ray examination of one of the sisters (PID 94) and the mother (PID 56) did not show the same abnormality in the thumb. The typical hand abnormality starts at the third finger. Syndactyly mainly affects the third and fourth fingers and extends to the fifth finger, whereas extra bones are present in only the third and fourth fingers. Of the 31 subjects, 22 (70.96\%) had clinodactyly associated with severe middle phalangeal hypoplasia of the fifth finger. The remaining nine showed only clinodactyly without hypoplasia of the same phalanx. No observations were made on hypoplasia of the middle phalanges of the third and fourth fingers because complex syndactyly or synostosis were possible. However, the middle phalanges were normal in the index fingers of all cases.

The proximal and distal phalanges of the halluces were found to be normal in all cases. There were variable degrees of hypoplasia of the middle phalanges in all four toes (fig 4D). Interestingly, similar hypoplasia was also seen in five persons who have bilaterally normal feet but with the characteristic SPD phenotype in their hands. The typical foot abnormality was fifth toe syndactyly/polydactyly. There was only one case of an enlarged and bipartite proximal phalanx of the second toe in addition to fifth toe synpolydactyly of both feet.

Radiological examination of the hands and feet of one of the non-penetrant cases (fig 3E, PID 27) was found to be completely normal.

(2) SUBJECTS EXHIBITING BOTH PRE- AND POSTAXIAL SYNPOLYDACTYLY SIMULTANEOUSLY The proband (fig 2, VII.3 and fig 3A, PID 73) is a 3 year old male who is affected with typical SPD in both hands (fig 7A). The feet showed six toes on both sides. However, the duplicated toe was on the preaxial side (first digit duplication) on the right, whereas it was postaxial (fifth digit duplication) on the left (fig 7B). $X$ rays of the feet showed biphalangeal big toe polydactyly on the right and fifth toe polydactyly on the left (fig 7C). There were five metatarsal bones on the right with an additional piece of bone seen between the fourth and fifth metatarsals. However, on the left foot six complete metatarsal bones were seen. No other associated abnormality was found.

Pedigree inspection showed that his father (fig 3A, subject 39) and paternal grandmother (fig $3 \mathrm{~A}$, subject 18 ) had enlarged halluces (fig $8 \mathrm{~A}, \mathrm{~B})$. This abnormality was on the left in the former (fig $8 \mathrm{~A}$ ), but on the right in the latter (fig 8B). We could not obtain their consent for radiological examination. However, there was no similar abnormality in the father's or the paternal grandmother's sibs.

(3) PERSONS MANIFESTING "POSTAXIAL POLYDACTYLY TYPE A"

The proband (fig 2, VI·101 and fig 3D, PID 59) was a 13 year old female who had postaxial polydactyly in both hands and in the left foot (fig 9A,B). Radiological examination showed 

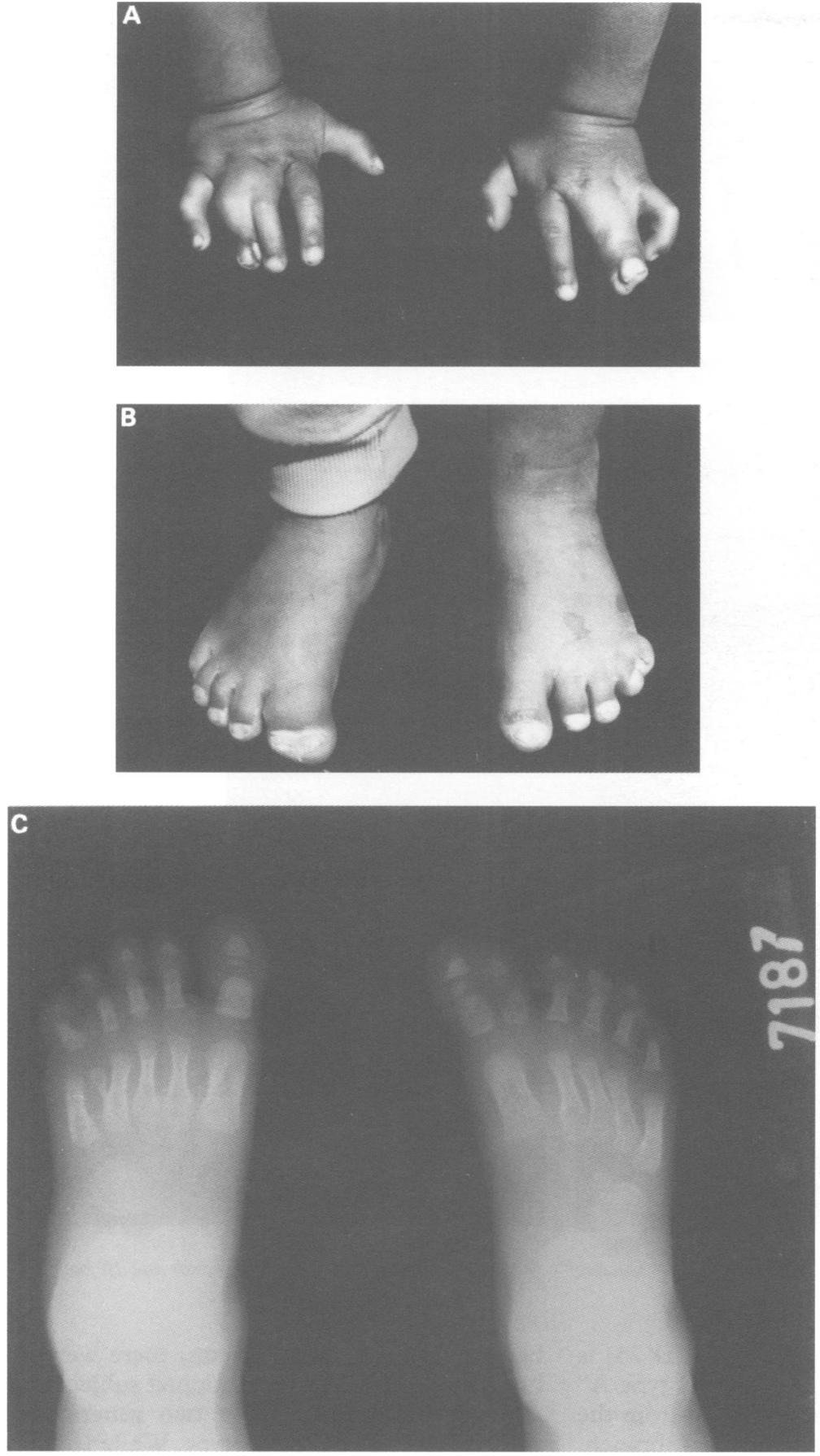

Figure 7 A-C Hands and feet of subject 73 in SPD-1 manifesting preaxial polydactyly on the right and postaxial polydactyly on the left foot. Both hands show the typical SPD phenotype.
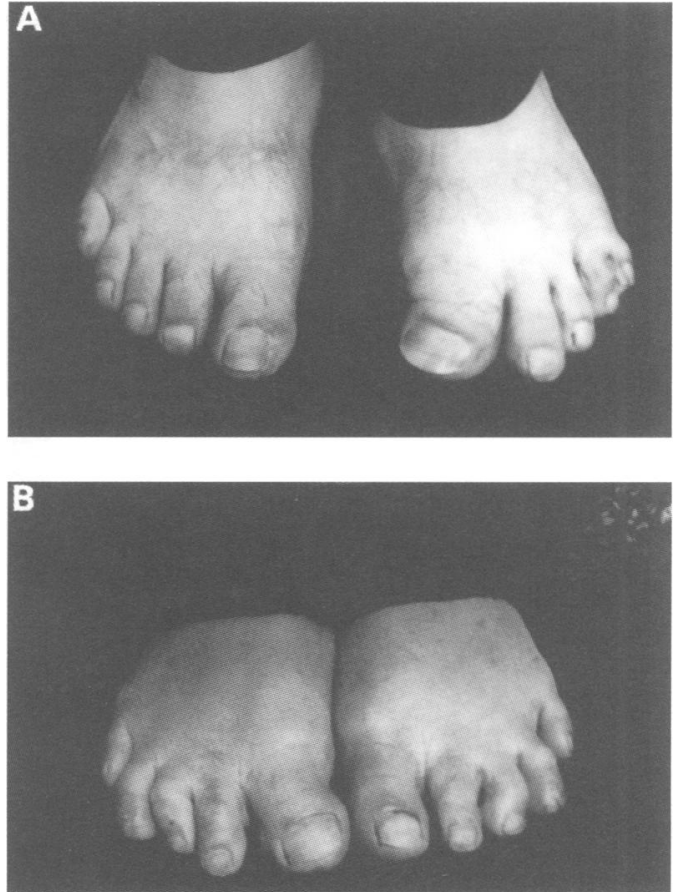

Figure $8(A)$ The enlarged hallux of the father (subject 39) of subject 73 in SPD-1 with manifestation of preaxial polydactyly on the right and postaxial polydactyly on the left foot. (B) The grandmother (subject 18, SPD-1) of subject 73 with the same enlarged hallux but on the opposite side.

foot. In this branch of the kindred, there were six subjects (fig 3D, PID 47, 54, 57, 58, 59, 61 ) with the same abnormality, all of whom were examined. $X$ rays were obtained from three of them (fig 3D, PID 47, 58, 59). Variable degrees of hypoplasia of the middle phalanges of the feet were documented in all three subjects. A previous generation (fig 3D, PID 12) had the same abnormality, which was described by his living non-penetrant heterozygous daughter. Despite the two people (fig 3D PID 47 and 61 ) with syndactyly that was associated with polydactyly of the feet, this abnormality apparently differed from typical SPD and represents an example of "postaxial polydactyly type A".

\section{FORMAL GENETICS}

As indicated previously, a total of 182 subjects are affected in the Derbent kindred, of whom 90 are male and 92 are female (male/female ratio of $1: 1.02)$. The comparable numbers for unaffected sibs are 74 males and 81 females. Taken together, this represents a total of 337 people (164 males, 173 females). Of a total of 325 living members of this kindred, 149 are affected, 138 are unaffected, and the remaining 38 are normal spouses married into the pedigree (table 2). Fifty of the 138 unaffected subjects were married, with a total of 191 normal offspring. There are four instances (fig 3A, PID 29; 3C, PID 39; 3D, PID 25; 3E, PID 27) of a skipped generation out of a total of 80 opportunities. These four matings were not consanguineous and illegitimacy is unlikely because of the conservative religious practices of members of this community. Since one of 

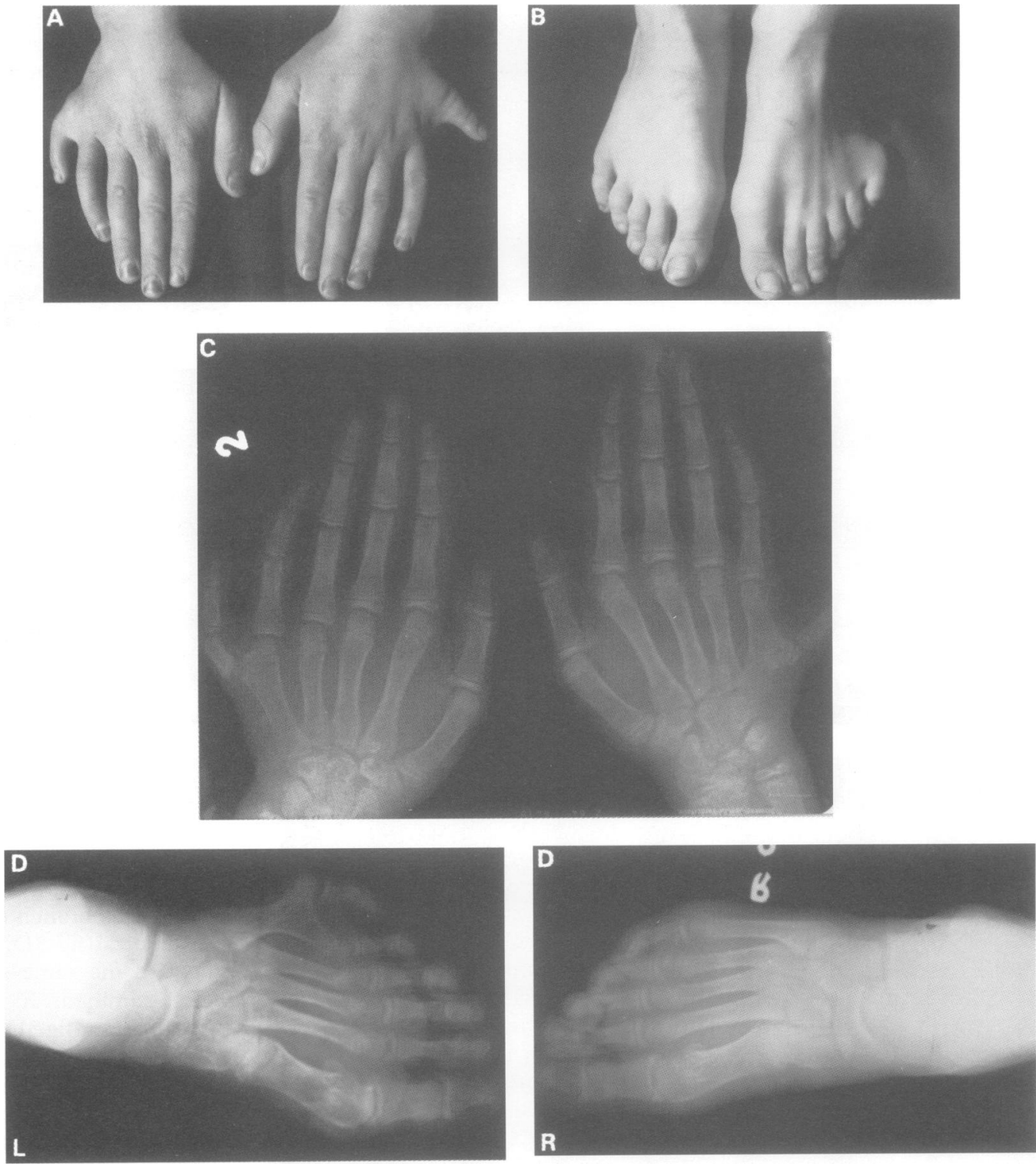

Figure 9 A-D Hands and feet of subject 59, SPD-4 showing "postaxial polydactyly type $A$ " on both hands and left foot.

these skipped generations (fig 3D, PID 25) is a member of a "postaxial polydactyly type A" branch, which is apparently different from the SPD phenotype, we excluded this branch. Thus, the estimated penetrance of SPD is $96 \%$. However, we also observed different penetrances between the upper and lower extremities. If we ignore eight pairs of marriages

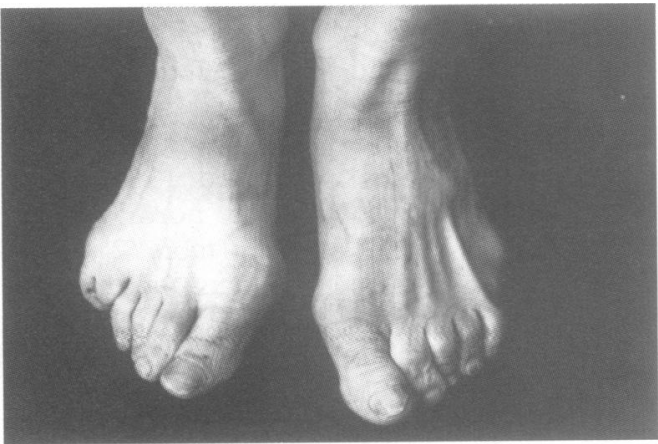

Figure 10 Subject 47 in SPD-4 with syndactyly which is associated with fifth finger polydactyly in a branch of a pedigree showing "postaxial polydactyly type $A$ ". between two affected subjects, there were 26 branches, including three skipped subjects examined consecutively over two generations, with the typical SPD phenotype. While 16 cases out of 26 transmitted the gene with abnormality in at least one foot, seven cases who had normal feet transmitted the gene to their offspring. In the remaining three cases with normal feet, the feet were also normal in their offspring. If the latter three cases are not taken into account, penetrance can be estimated as $69.5 \%$ in the feet. On the other hand, all affected children with hand abnormalities themselves had parents with affected hands (except non-penetrant parents). So the penetrance in the hands remains the same as the overall penetrance for the SPD phenotype (that is, $96 \%$ ).

\section{Discussion}

The work presented here appears to be the largest sample ever reported. Before this study, in 1927, Thomsen ${ }^{5}$ reported the most extensive pedigree, which included 42 affected subjects over seven generations. Although we traced the 
SPD phenotype back at least 140 years, we have not been able to verify that the gene in these families started from one person. However, we were able to trace it back to four families in the first or second generations. Two brothers (fig $2, \mathrm{II} \cdot 2$ and II.3) were known to have had the malformation. Two sisters (fig 2, III.19 and III.20) were also known to have been affected, but information on their parents is lacking. Thus, we assumed that either parent of each of these four subjects had the condition, since the possibility of the occurrence of more than one mutation in such a small community is unlikely. We believe that the founder effect in this village has contributed to such an extensive pedigree. Of course, one would expect that the birth of new subjects continuously increases the size of this family tree.

Further analysis of this extraordinary kindred from Turkey showed that most of the patients had the basic feature of syndactyly type $\mathrm{II}^{1}$ or an increased number of digits on the mesoaxial line with normal pattern formation. ${ }^{4}$ However, there are some cases which one would have not expected to see in this kindred, such as pre- and postaxial polydactyly in the same person and "postaxial polydactyly type A" in that kinship. These unusual findings will shed light on the phenotypic expression of the SPD gene.

Typical SPD phenotypes were observed in $84.9 \%$ of affected subjects who were physically examined with mesoaxial anomalies in the hands and postaxial deformities in the feet. Radiological examination of 31 typical SPD cases showed that numerical and structural anomalies of metacarpal and metatarsal bones may have occurred, whereas carpal and tarsal bones were normal in all cases. Metacarpal and metatarsal involvement has frequently been reported in other published pedigrees ${ }^{6-8}$ and these should be taken as the basic feature of synpolydactyly, as suggested by Merlob and Grunebaum. ${ }^{9}$

We also suggest that variable degrees of middle phalangeal hypoplasia of the fifth fingers on the hands and the second to fifth toes may be another feature of synpolydactyly. We also observed the same middle phalangeal hypoplasia in SPD patients with normal feet. This inherited association raises the question of whether middle phalangeal hypoplasia is a minor expression of the SPD gene. However, the same findings were not observed in one fully non-penetrant case. This observation suggests that the mutant gene may have a gradation of manifestation from hypoplasia of the middle phalanges to typical presentation of the feet.

Cross $\mathrm{et} \mathrm{al}^{7}$ suggested that the malformation is never present in the feet unless the hands are also affected. This observation is supported by our data. On the other hand, the report by some authors of less frequent involvement of both hands and feet in females was not supported in the present work. ${ }^{2}$

In the hands, the involvement was bilateral in $96.7 \%$ of cases, so the asymmetry of the findings is not comparable. However, with respect to involvement of the feet, it seems that females are affected more on the right side.

The SPD phenotype in this kindred is in- herited as an autosomal dominant trait with reduced penetrance, which is consistent with previously reported families. ${ }^{179}$ However, penetrance is different between the upper and lower extremities and is estimated to be $96 \%$ and $69.5 \%$, respectively. The excess of affected males noted by some authors is not supported by the Derbent kindred. ${ }^{1}$ In this kindred, the sex ratio almost exactly fits $1: 1$.

With respect to phenotypic differences seen in this kindred, we found subjects with preaxial and postaxial polysyndactyly simultaneously. These cases can be distinguished from Greig cephalopolysyndactyly mainly by the lack of any other associated abnormality. ${ }^{10}$ Furthermore, this polydactyly branch is apparently related to the other branch showing typical SPD. To the best of our knowledge, these are the first synpolydactyly cases showing preaxial and postaxial polysyndactyly on the feet ever described.

During the field study, we observed a family with "postaxial polydactyly type A" in a branch of this kindred. This branch was related to the typical SPD branch through subjects 3 and 5 according to the records of birth and date (fig 3D). However, nobody remembers whether these people were affected or not. So, this unusual feature would be either information bias or a new mutation. Because of insufficient data, the interpretation and significance of this branch in the overall kindred remain unknown. However, if we assume there is no information bias in this branch of the kindred, observing all three deformities (that is, preaxial, mesoaxial, and postaxial) of an increased number of digits with normal pattern formation according to the classification of Winter and Tickle $^{4}$ in one kindred is very interesting.

In a review of recent advances in the genetics of human limb development, the role of a number of important genes in the aetiology of syndactyly/polydactyly has been recognised. ${ }^{11}$ Molecular genetic study of these genes in the Derbent kindred may shed light on the aetiology of this phenotype. Recently a number of abnormalities in families with different types of polydactyly/syndactyly have been mapped to both arms of chromosome $7 .{ }^{12-14}$ Genetic linkage study of 11 markers from the entire length of this chromosome in the Derbent kindred did not show any evidence for location of the SPD locus on this chromosome. Further studies are currently under way in our laboratory to map the SPD locus in this kindred.

This study would not have been possible without the cooperation of affected subjects and their families, to whom the author express their deepest appreciation. We would like to thank the Basic Health Services of the Turkish Ministry of Health for providing facilities, generous support, and assistance during this study. We would also like to thank Dr P Erdogdu from the Ministry of Health for her personal assistance during the ascertainment of the SPD kindred. This work is supported by Faculty Research Grant from the University of Connecticut Health Center. The work described here was originally presented for fulfilment of a PhD degree (A N Akarsu)

1 Temtamy SA, McKusick VA. The genetics of hand malformations. In: Birth defects: original article series. Volume formations. In: Birth defects: original article series. Volume

2 McKusick VA. Mendelian inheritance in man. Catalogue No 186000. 10th ed. Baltimore: The Johns Hopkins

3 Sener RN. Case report 636 . Tetrapolysyndactyly with postaxial type of polydactyly. Skeletal Radiol 1990;19:542-6. 
bryological overview and suggested classifications. Eur Hum Genet 1993;1:96-104.

5 Thomsen O. Einige Eigentuemlichkeiten der erblichen Poly- und Syndaktylie bei Menschen. Acta Med Scand 1927;65:609-44.

6 Pipkin SB, Pipkin AC. Variation of expression of polydactyly. f Hered 1946;36:93-6.

7 Cross HE, Lerberg DB, McKusick VA. Type II syndactyly. Am f Hum Genet 1968;20:368-80.

8 Ridler MAC, Laxova R, Dewhurst K, Saldana Garcia P. A family with syndactyly type II (synpolydactyly). Clin Genet 1977;12:213-20.

9 Merlob P, Grunebaum M. Type II syndactyly. Am f Hum Genet 1968;23:237-41.
10 Gollop TR, Fontes LR. The Greig cephalosyndactyly syndrome: report of a family and review of the literature. $A m$ Med Genet 1985;22:59-68.

11 Roberts DJ, Tabin C. The genetics of human limb development. Am f Hum Genet 1994;55:1-6.

12 Tsukurov O, Boehmer A, Flynn J, et al. A complex bilateral polysyndactyly disease locus maps to chromosome $7 \mathrm{q} 36$. Nature Genet 1994;6:282-6.

13 Heutnik P, Zguricas J, Van Oosterhout L, et al. The gene for triphalangeal thumb maps to the subtelomeric region of chromosome 7q. Nature Genet 1994;6:287-92.

14 Vortkamp A, Gessler M, Grzeschik KH. GL13 zinc-finger gene interrupted by translocations in Greig syndrome families. Nature 1991;352:539-40. 